\title{
Chronic bottom trawling alters the functional composition of benthic invertebrate communities on a sea-basin scale
}

\author{
H. M. Tillin ${ }^{1,3}$, J. G. Hiddink ${ }^{1, *}$, S. Jennings ${ }^{2}$, M. J. Kaiser ${ }^{1}$ \\ ${ }^{1}$ School of Ocean Sciences, University of Wales, Bangor, Menai Bridge, Anglesey LL59 5AB, UK \\ ${ }^{2}$ Centre for Environment, Fisheries and Aquaculture Science (CEFAS), Lowestoft Laboratory, Pakefield Road, Lowestoft, \\ Suffolk NR33 0HT, UK
}

${ }^{3}$ Present address: School of Biological Sciences, Biosciences Building, University of Liverpool, Crown Street, Liverpool L69 7ZB, UK

\begin{abstract}
Bottom trawling causes widespread physical disturbance of sediments in seas and oceans and affects benthic communities by removing target and non-target species and altering habitats. One aspiration of the ecosystem approach to management is to conserve function as well as biodiversity, but trawling impacts on benthic community function need to be understood before they can be managed. Here we present the large scale and long term impact of chronic trawling on the functional composition of benthic invertebrate communities using a comprehensive set of functional traits. The effects of chronic trawling disturbance on the functional composition of faunal benthic invertebrate communities, as sampled with a small beam trawl, were investigated at 6 to 13 sites in each of 4 contrasting regions of the North Sea. Each site was subject to known levels of trawling disturbance. Information on the life history and ecological function traits of the taxa sampled was translated into fuzzy coding and used to analyse the relationship between life history and functional roles within the ecosystem. Multivariate analyses were used to examine changes in the distribution of traits over gradients of trawling intensity. Changes in the functional structure of the community due to the effects of long-term trawling were identified in 3 of the 4 areas sampled. Filter-feeding, attached and larger animals were relatively more abundant in lightly trawled areas, while areas with higher levels of trawling were characterised by a higher relative biomass of mobile animals and infaunal and scavenging invertebrates. Univariate analysis of selected traits confirmed the patterns observed in multivariate analysis. These results demonstrate that chronic bottom trawling can lead to large scale shifts in the functional composition of benthic communities, with likely effects on the functioning of coastal ecosystems.
\end{abstract}

KEY WORDS: Benthic invertebrates $\cdot$ Biological traits $\cdot$ Fuzzy coding $\cdot$ Fishing $\cdot$ Ecosystem functioning Resale or republication not permitted without written consent of the publisher

\section{INTRODUCTION}

The growing commitment to an ecosystem approach to fisheries means managers need to take into account the wider environmental impacts of fishing (Sinclair \& Valdimarsson 2003, Pikitch et al. 2004). Bottom trawling has extensively documented and global impacts on benthic communities and habitats, leading to reduced biomass, production and diversity (e.g. Hall 1999, Kaiser \& De Groot 2000, Hiddink et al. 2006).
Changes in species composition may alter the functional diversity of communities and modify ecosystem functioning (Chapin et al. 1997, Diaz \& Cabido 2001, Tilman 2001, Solan et al. 2004). Species process resources at different rates and through different pathways, and also differ in the effects they have on the physical environment and in interactions with other species. The range and value of functional traits in a community will determine its functional diversity (Diaz \& Cabido 2001). Functional diversity has been shown 
to maintain ecosystem processes in some communities (Diaz \& Cabido 2001, Tilman 2001), but the effects are more idiosyncratic in others (Emmerson et al. 2001). Key to understanding the effect of trawling disturbance on the functioning of benthic ecosystems is the relationship between the function of species and their vulnerability to trawling disturbance (Larsen et al. 2005). If extinction order is not random with regard to ecological function, the impact of trawling on ecosystem functioning is likely to be much larger than when extinctions are random (Solan et al. 2004, Gross \& Cardinale 2005). Thus, it is important to understand whether trawling impacts ecosystem performance through non-random extinctions of functional groups.

In general, body size and life history are correlated. In the benthos, larger organisms have lower natural mortalities, slower growth and lower annual reproductive output, increased longevity and lower natural rates of intrinsic increase (Brey 1999). Species with large body sizes are therefore less able to compensate for high mortality rates inflicted by bottom trawling than smaller sized species that have faster life cycle rates and higher reproductive output. As a result, benthic communities in trawled areas are dominated by smaller species with higher productivity per unit biomass or by highly mobile epibiota (Kaiser et al. 2000, Jennings et al. 2001). Therefore, if life history is strongly correlated with function, then the impact of trawling on productivity and other processes is likely to be larger than when body size and ecological function are not correlated (Thrush \& Dayton 2002). To date the relationship between body size and ecological function has not been tested.

Large parts of most shelf seas have been intensively exploited by bottom trawlers for decades. Assessing the long term and large scale impact of chronic bottom trawling on ecosystem functioning should therefore have priority in studies of the impact of bottom trawling. However, hitherto most studies have focussed on assessing the small scale and relatively short term effect of trawling in experimental studies (for overview see Collie et al. 2000b, Kaiser et al. 2006). Although these studies provide useful insights into the short-term effects of physical disturbance, they do not further our understanding of likely long-term changes. Comparison of the current composition of benthic communities with historical data can yield information on relevant temporal and spatial scales, but it is difficult to separate bottom trawling impacts from other environmental changes (Rumohr \& Kujawski 2000, Robinson \& Frid 2005). More relevant for the study of the long term effect of chronic trawling on the functional composition of the benthos are large-scale studies that compare areas with known differences in commercial bottomtrawling history. Unfortunately, many of these studies do not have spatial replicates because of the lack of detailed spatial effort distribution data and the scarcity of marine reserves that might act as reference points (e.g. Bradshaw et al. 2003, Bremner et al. 2003b). Up to now, only a few large scale studies that examined the benthic functional composition had an experimental design that enabled the observed effects to be attributed to chronic trawling disturbance (Collie et al. 1997, Thrush et al. 1998, Collie et al. 2000a, McConnaughey et al. 2000), but none of these has examined a comprehensive set of functional traits. Generally, these studies found a negative impact of trawling on sessile, colonial epifauna and bushy animals, long lived surface dwellers, and positive effects of trawling on deposit feeders, opportunists and small animals (Peterson et al. 1987, Collie et al. 1997, Thrush et al. 1998, Watling \& Norse 1998, Collie et al. 2000a, Rumohr \& Kujawski 2000, Bradshaw et al. 2003, Bremner et al. 2003a). Different studies found contradictory the responses of both scavengers and predators to trawling (Thrush et al. 1998, Rumohr \& Kujawski 2000, Bremner et al. 2003a).

The present study examines the large scale and long term impact of chronic trawling on the functional composition of benthic invertebrate communities using a comprehensive set of functional traits. Biological trait analysis considers a range of biological taxon characteristics to assess how functioning varies between assemblages. Trait analysis is a potentially useful approach for assessing ecosystem function on both large and small scales in benthic environments (Bremner et al. 2003a, Bremner et al. 2003b). This paper investigates the effects of bottom trawling on life history and a range of ecological functional traits of benthic invertebrate communities. We analysed the trait composition of benthic invertebrate communities from 4 areas that covered a wide range of habitats in the North Sea, over a gradient of trawling intensities in each area. The relationship between life history and ecological function was examined to determine if species in similar functional groups have equivalent life histories. If life history traits influence the impact of trawling on population size, this correlation indicates the probability of functional group extinction and identifies which ecological functions are most likely to be affected by bottom trawling. The current study is unique because it examines the impact of trawling on a large set of ecological and life history characteristics and the relationship between these parameters, and on a much larger spatial scale $(400 \mathrm{~km})$ than previous studies while controlling for differences between habitats and using spatially detailed fishing effort data. Because of the general nature of the analysis of ecological function, the range of habitats considered and the large scale examined, our results are likely to be applicable to shelf seas in other geographic regions. 


\section{MATERIALS AND METHODS}

Study area. Beam and otter trawls are 2 of the most widely used fishing gears in the North Sea. Otter trawls are mainly used in the northern North Sea in fisheries for Nephrops norvegicus and gadoids. Beam trawls have been used since the 1970s in the southern North Sea to catch flatfish (Jennings et al. 1999a). Bottom trawling continues throughout the year. Assessments of the effects of trawling were based on measurements of the biomass of benthic communities at stations subjected to different levels of fishing intensity in 4 areas with different habitat types (in terms of sediment, depth and tidal currents; Table 1, Fig. 1). Each area was characterized by strong gradients in trawling intensity and relative homogeneity of physical habitat.

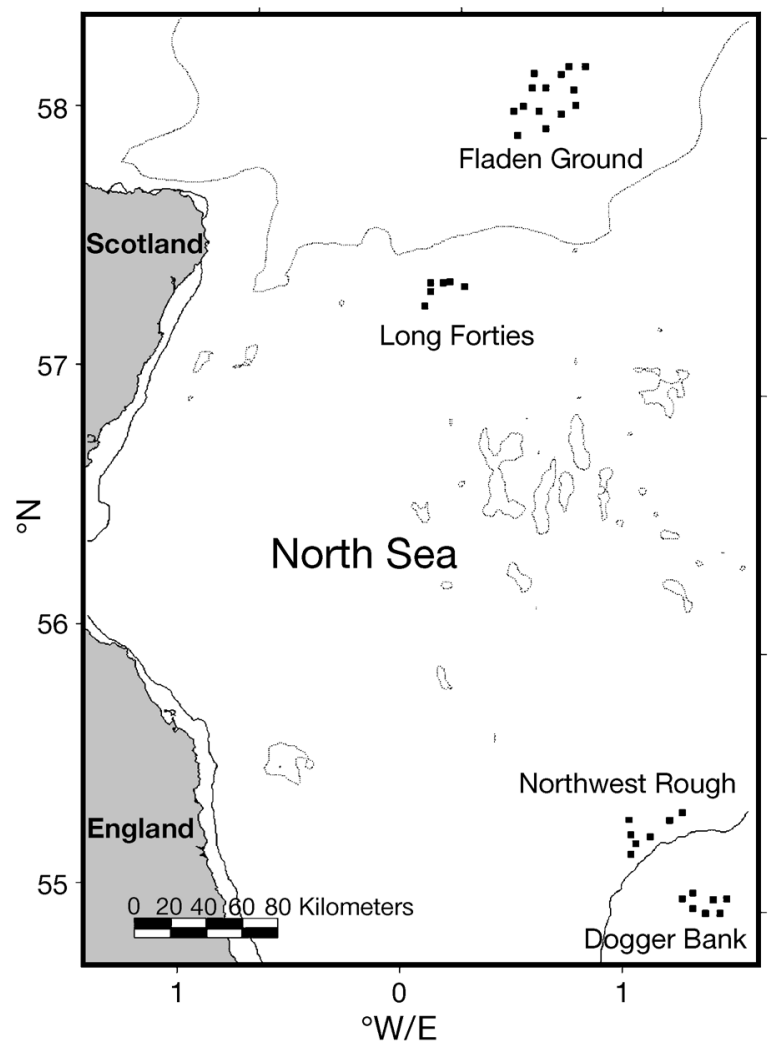

Fig. 1. Study area. Sampling areas with stations (匹) and 40 and $100 \mathrm{~m}$ isobaths (black and grey lines, respectively)
We made sure no correlation existed between trawling intensity and known environmental parameters like sediment composition, depth and tidal currents. We expected trawling effort to be spatially heterogeneous in areas of homogeneous habitat because fishers tend to trawl along paths that are recorded in their navigation systems and are known to be free of obstructions, like wrecks and pipelines, that could damage the trawl gear (Auster \& Langton 1999, Holland \& Sutinen 2000). This pattern of effort within habitats persists over many years and Dinmore et al. (2003) showed that unfished areas are not necessarily unsuitable for trawling. Regular trawling may make the seabed more suitable for trawling by removing boulders and large sessile fauna like sponges, and may improve feeding conditions for some commercial fish species (Rijnsdorp \& Vingerhoed 2001). Nevertheless, fishermen try to avoid areas where fish catches are low (although they do not always succeed in this, Murawski et al. 2005), and therefore may select areas with a particular benthic community composition. Thus, when using existing gradients in trawling intensity the possibility exists that, even if trawling has no impact on the benthos, differences in community composition that seem to be related to trawling intensity can be found. This is a general problem of comparative fishing impact studies and this problem is not avoided by studies comparing fished areas with marine reserves or closed areas (e.g. Engel \& Kvitek 1998, Collie et al. 2000a) because marine reserves, like terrestrial reserves, are unlikely to be randomly situated with regard to ecosystem productivity and biodiversity. The design of comparative fishing studies is further complicated because trawling is likely to affect sediment characteristics (e.g. Palanques et al. 2001, Trimmer et al. 2005). We tried to avoid confounding of trawling impacts by examining large trawling gradients in relatively small areas while minimizing differences in environmental conditions. Therefore, within the individual study areas, trawling effort distributions were unlikely to be related to patterns in ecosystem productivity. Previous studies have shown that trawling can have a much larger impact on benthic communities than can be expected from small differences in environmental conditions (e.g. Jennings et al. 2001, Hermsen et al. 2003). However, in the

Table 1. Characteristics of the sampled areas/stations

\begin{tabular}{|c|c|c|c|c|c|c|}
\hline Area & $\begin{array}{l}\text { Depth } \\
\text { (m) }\end{array}$ & Sediment & $\begin{array}{l}\text { Bottom shear } \\
\text { stress }\left(\mathrm{N} \mathrm{m}^{-2}\right)\end{array}$ & $\begin{array}{l}\text { Trawling intensity }\left(\mathrm{yr}^{-1}\right) \text { : } \\
\text { min-max }\end{array}$ & $\begin{array}{l}\text { No. of stations } \\
\text { sampled }\end{array}$ & Sampling dates \\
\hline Dogger Bank & $25-30$ & Sand & $0.10-0.15$ & $0.2-4.9$ & 7 & September 2003 \\
\hline Fladen Ground & $142-153$ & Mud & $0.08-0.11$ & $0.2-3.0$ & 13 & June 2004 \\
\hline Long Forties & $74-83$ & Gravelly sand & $0.30-0.36$ & $0.05-1.1$ & 6 & September 2003 \\
\hline Northwest Rough & $49-63$ & Sand & $0.11-0.17$ & $0.1-8.2$ & 7 & March 2003 \\
\hline
\end{tabular}


current and other comparative studies, small differences in benthic communities may be due to differences in environmental conditions and therefore have to be interpreted with care. Because it is not feasible to experimentally trawl studies over relevant temporal and spatial scales, and because of the lack of large untrawled areas, comparative studies are the only practicable option to study the large scale and long term effect of chronic trawling.

Within each area, 6 to 13 stations were selected; all had the same sediment-type according to British Geological Survey sediment maps (based on the proportion of gravel, sand and silt in the sediment, British Geological Survey 2002) and similar environmental conditions of other kinds (depth, seabed shear stress, chlorophyll a content of the sediment; see Table 1, data from Hiddink et al. 2006). Stations were defined as $6.25 \mathrm{~km}^{2}$ boxes. The maximum distance between stations within an area varied between 19 and $43 \mathrm{~km}$.

Trawling intensity. High resolution fishing effort data were obtained from the Vessel Monitoring System (VMS), a satellite tracking system of fishing vessels over $24 \mathrm{~m}$ length overall. In the offshore areas we studied, very few vessels below this size operate. Dinmore et al. (2003) gives a more detailed description of the use of VMS data. Since 1 January 2001 all EU fishing vessels $>24 \mathrm{~m}$ length on trips for more than $24 \mathrm{~h}$ have been required to report their position via satellite to monitoring centres in their flag states at $2 \mathrm{~h}$ intervals. The speed of vessels can be determined from 2 consecutive position records and after eliminating stationary vessels and those that are assumed to be cruising $(>8$ knots), the number of trawl passes per unit area per unit time can be calculated (Dinmore et al. 2003). Trawling intensity was expressed as the average area covered by trawling in a year $\left(\mathrm{yr}^{-1}\right)$, e.g. a trawling intensity of $2 \mathrm{yr}^{-1}$ means that an area was trawled twice a year. For the calculation of yearly trawling intensity it was assumed that trawlers fished at a speed of 5 knots with a fishing gear width of $24 \mathrm{~m}$ i.e. either one $24 \mathrm{~m}$ wide otter trawl or two $12 \mathrm{~m}$ wide beam trawls (Jennings et al. 2002). We used the average trawling effort over $2 \frac{1}{2}$ yr period because recovery from trawling probably takes at least $2 \frac{1}{2}$ yr (Blyth et al. 2004) and in many systems probably much longer than that (Hermsen et al. 2003). Obviously, the exact time since the last trawling disturbance will have had an effect on the current local community composition. We assumed that the relatively large area $\left(>900 \mathrm{~m}^{2}\right)$ covered by the three 2-m-beam trawl samples overlapped many recent and old trawl tracks and assured that the average trawling intensity over the last $2 \frac{1}{2}$ years was a good descriptor of the trawling disturbance experienced by the sampled community. We will discuss later what the implications of the different sampling seasons for the different areas (March, June and September) are for the interpretation of our results.

Sampling of the invertebrate community. Benthic invertebrates were sampled with a 2-m-beam trawl fitted with a chain mat and a 2-mm-mesh liner (Jennings et al. 1999b). The trawl was towed at a speed of $0.8 \mathrm{~m}$ $\mathrm{s}^{-1}$ for $5 \mathrm{~min}$. The towing period was timed from the moment that the net contacted the seabed until the moment of hauling. Start and end positions for the beam trawl hauls were recorded using the ships Differential Global Positioning System (DGPS) and the towed distance $(\mathrm{m})$ calculated from these positions. Three replicate samples were taken at haphazard positions, but trawling direction was usually dictated by the direction and strength of tidal currents and wind. All organisms taken in the beam trawl sample were removed for processing. Samples were sorted and identified to the lowest taxonomic level possible and wet weights were recorded for individual animals and colonies. Animals that inhabited shells they did not secrete were removed from these shells for weight determination (e.g. hermit crabs Pagurus sp.). The biomass of species in the 3 replicate samples for each station were summed and converted into values of biomass $1000 \mathrm{~m}^{-2}$ to standardise data collected among stations and areas. Samples from the Long Forties grounds contained large masses of entangled hydroids and bryozoans; because separating these was unfeasible they were weighed together. No sampling gear representatively samples the entire benthic invertebrate community, and the 2-m-beam trawl is not particularly efficient (Kaiser et al. 1994, Reiss 2005). Although a 2-m-beam trawl primarily catches epifaunal animals, some infaunal animals like bivalves are also sampled. In the rest of this paper we will use the term 'benthic invertebrate community' for all animals caught using the 2-m-beam trawl, and thus our data represent only that component of the assemblage sampled by this gear.

Analysis overview. To predict whether the functional diversity of areas is likely to be altered by trawling or not, selected life history characteristics of species were compared with characteristics that describe their functional attributes. The relationship was tested using variables for both life history and ecological function coded in a way known as fuzzy coding (codage flou) and compared using the RELATE routine in the computer package Primer (Clarke \& Warwick 1994). Fuzzy coding provides a description of species traits by the distribution of species attributes across a range of trait modalities (categories) defined from knowledge of biological and ecological characteristics (Chevenet et al. 1994). The functional diversity of benthic invertebrate communities across the trawling gradients in each area was described using a form of 
correspondence analysis with separate factorial analysis of life history and ecological traits. Changes in functional structure were analysed further by conducting linear regression on selected characteristics. The methods are explained in more detail below.

We based our analysis of changes in functional composition on biomass because many important ecological processes are strongly affected by functional group biomass. Additionally, unlike e.g. numerical density or body size, biomass can be summed within functional groups in a meaningful way. Furthermore, some organisms, such as bryozoans, cannot be counted easily.

The effect of trawling on biomass, production and species richness of benthic infaunal and epifaunal communities on the Dogger Bank, Northwest Rough and Fladen Ground is presented in different papers (Hiddink et al. 2006, Queirós et al. 2006).

Fuzzy coded species databases. Data were gathered from the literature on 6 life history and 4 ecological functional traits for each taxon (see sections below). The information was used to produce taxon tables containing information on the life history variables and ecological function variables. Each trait variable was broken down into a number of modalities (categories) chosen to encompass the range of possible attributes of all species. For example, the ecological functional trait 'adult mobility' was separated into the following modalities; 'permanently attached', 'temporarily attached', 'sedentary', 'burrower', 'crawler' and 'swimmer'. Taxa were scored for their affinity to each modality of each variable using fuzzy coding. Fuzzy coding allows taxa to exhibit categories of a variable to different degrees (Chevenet et al. 1994). Fuzzy coding is an appropriate measure as functional traits are not necessarily absolute but are modified on temporal and spatial scales, e.g. feeding in the amphiurid brittle star Amphiura filiformis is related to the tidal cycle switching from filter feeding when current velocity is high to deposit feeding at depth when current velocities are low (Solan \& Kennedy 2002). In this study, species were assigned to modalities by 5 different codes, where 4 = total affinity with a trait and $0=$ no affinity. The hermit crab Pagurus bernhardus, which is primarily a deposit feeder, then an omnivorous scavenger which occasionally filter feeds and acts as a predator was assigned as; Deposit Feeder $=3$, Filter feeder $=1$, Scavenger $=2$ and Predator $=1$. These scores were converted into percentages $(P$. bernhardus becomes $43,14,29,14)$ to provide uniform row totals for the subsequent RELATE analyses. We assumed that species exhibited the same biological traits throughout the North Sea, regardless of the habitat, as it is impossible to find habitat dependent trait information for most species.

To reduce the demand for biological trait data while minimizing the impact on the conclusions, only ani- mals that were present in the top $90 \%$ of biomass at any station in the Dogger Bank (DB), Northwest Rough (NW) and Long Forties (LF) areas were used in the analysis. Species that made up to $99 \%$ of the biomass in the Fladen Ground (FG) area were included to compensate for the high dominance of Pandalus borealis in samples. This approach retained those species that represented most of the biomass while removing the rarer species, about which little or no reliable ecological and life history information was available. A total of 54 taxa was examined. These were identified to the nearest practicable taxonomic level, varying from species to genus and phylum. The final taxa subset was divided among phyla as follows: 1 Porifera; 13 Mollusca; 1 Hemichordata; 15 Echinodermata; 14 Crustacea; 2 Bryozoa; 4 Cnidaria; and 3 Annelida. We also used a mixed entry of Bryozoa/Cnidaria to code for the mixed sample of hydroids and bryozoans. The data gathered on the species with an attributed reference list are in the appendices (available as Supplementary Material at www.int-res.com/articles/ suppl/m318p031_app.doc).

Data on marine benthic invertebrates are widely scattered, and thus a wide variety of information resources was used, including the journal abstract services BIOSIS and ASFA and the website of the Marine Life Information Network (www.marlin.ac.uk). Where the available data were supplemented by using information from congener species, this is indicated in the table. Information on the ecology of species proved easier to find than life history information. Missing data were based on knowledge of the ecology and life histories of similar species and for life history parameters from body size. The validity of this approach relies on the fact that there are consistent links between body size and life history. However, this means that the power to detect differential effects of trawling on different life history parameters was reduced. Where a characteristic was inferred from another modality, this is identified as 'inferred' in the appendices, e.g. species that are deposit feeders are inferred to feed on organic detritus.

The biomass of the mixed sample of hydroids and bryozoans sampled at LF was used in the modality weighting for the fuzzy coded ecological trait table (see below). Ecologically they are similar and could be assigned to modalities in a similar way. However, they differ in life history characteristics and were therefore excluded from the RELATE and life history analyses.

Ecological functional characteristics. The variables describing ecological function were chosen to include the characteristics that we considered to have the strongest effect on energy flow in the ecosystem and likely to be available for most species (see Table 2 for the categories and modalities). Functional traits most 
Table 2. Ecological function variables and modalities. For examples of species in each modality, see appendices (available as Supplementary Material at www.int-res.com/articles/ suppl/m318p031_app.doc)

\begin{tabular}{|ll|}
\hline Variable & Modality \\
\hline Mobility & Permanently attached \\
& Temporarily attached \\
& Sedentary \\
& Burrower \\
& Crawler \\
& Swimmer \\
Habitat & Infaunal \\
& Epifaunal \\
Feeding type & Epizoic (living on other animals) \\
& Deposit \\
& Filter/suspension \\
& Browser \\
Scavenger \\
Food & Predator \\
& Macroalgae \\
& Invertebrates \\
& Carrion \\
& Detritus \\
& Plankton \\
& Suspended organic matter \\
& Microorganisms \\
\hline
\end{tabular}

likely to have profound effects on ecosystem processes are those that (1) modify the availability, capture and use of abiotic resources and (2) affect the feeding relationships (trophic structure) within a community (Chapin et al. 1997). Two variables relating to resource dynamics through supplies of nutrients and space ('movement' and 'habitat') and 2 variables reflecting trophic structure ('feeding type' and 'food type') were used to depict these. Within these variables the modalities were chosen to cover the possible range of types. Within this study, we defined the modality 'filter feeder' to include organisms such as bivalves that can also be classed as suspension feeders.

Life history characteristics. Life history characteristics were chosen to discriminate among taxa on the basis of vulnerability to trawling (Table 3). Each variable described an aspect of life history that is known to influence trawling vulnerability and the modalities within each variable were chosen to divide species as much as possible into either low or high vulnerabilities. Modeling and previous studies have shown that the composition of trawled invertebrate communities tends to shift in favour of species with typical $r$-selection traits: short lifespan allied with fast growth and early onset of sexual maturity. The life history characteristics used to reflect this were 'size', 'maximum longevity', 'age of sexual maturity' and 'reproductive frequency'. The weight of the heaviest individual of each taxon was used to assign the taxa to one of the size modali-
Table 3. Life history variables and modalities. For examples of species in each modality, see appendices (available as Supplementary Material at www.int-res.com/articles/suppl/ m318p031_app.doc)

\begin{tabular}{|ll|}
\hline Variable & Modality \\
\hline $\begin{array}{l}\text { Size (maximum } \\
\text { wet weight from }\end{array}$ & Small, $<1$ \\
samples) (g) & Small-medium, 1.1-5.0 \\
& Medium, 5.1-15 \\
& Large, 40.1-200, 15.1-40 \\
& Very large, 201+ \\
Longevity (yr) & $<2$ \\
& $2-5$ \\
& $6-10$ \\
& $10+$ \\
Age at which & $<2$ \\
sexual maturity & $2-5$ \\
is reached (yr) & 6-10 \\
& 10+ \\
Reproductive & Asexual \\
technique & Sexual, spawning \\
& Sexual, ovigerous \\
& Sexual, direct development \\
Reproductive & Annual, 2 or more reproductive events \\
frequency & Annual, 1 reproductive event \\
& Biennial \\
& Semelparous \\
Dissemination & No pelagic phase \\
& Pelagic larval phase \\
& Adult of low mobility \\
& Adult of high mobility \\
& Migratory \\
\hline
\end{tabular}

ties. These 4 traits are typically correlated with one another according to life history theory (Stearns 1992) and therefore one is likely to be as good a measure of vulnerability to trawling as any other. For the purpose of our multivariate analysis, however, including 4 correlated life history traits makes the results less sensitive to the particular chosen trait.

Other trait variables included were 'reproductive technique' and 'dissemination'. Species that can disperse widely either by having pelagic larvae and/or active mobile, migratory adults are predicted to have an advantage in recolonising trawled areas compared to species for which reproduction is by direct development and adults have low mobilities. To a certain extent the category may be seen to overlap the first ecological character: 'movement'; but in this case the variable aim is to elucidate the potential of long-range dispersal, hence the inclusion of a modality concerning larval development. In marine systems community composition has been linked strongly to patterns in recruitment as well as competition for resources (Olafsson et al. 1994).

Correlation between ecology and life history. The correspondence between life history characteristics 
and ecological function was investigated using the fuzzy coded traits for the species in each area. The trait scores were standardized for each species by recoding the scores as percentage frequencies (as above). The Bray-Curtis similarity matrices of each table were compared using the RELATE function within the PRIMER package (Plymouth Routines in Marine Research, Clarke \& Warwick 1994). The $\rho$ statistic indicates the degree of correlation between the similarity matrices of the fuzzy coded life history trait table and the ecological character trait table. Where $\rho=1$ there is a perfect match between the tables and $\rho=0$ indicates there is no correlation. The significance of the correlation was tested using PRIMER, which runs 999 multiple permutations of the data sets.

Relationship between functional composition and trawling intensity. To assess functional diversity changes between stations in each area, a table of stations by biomass-weighted modalities was produced for each area. The biomass for each species was multiplied by its modality scores within each variable. These were then summed for each modality to produce biomass weighted life history and ecological function tables for all stations. These tables were analysed separately by Fuzzy Correspondence Analysis (FCA) using the multivariate analysis software package ADE-4 (Thioulouse et al. 1997).

FCA is a type of correspondence analysis used when variables are fuzzy coded. This analysis is also known as a multiple correspondence analysis (MCA) extended to non-disjunctive arrays (Chevenet et al. 1994). Correspondence analysis was developed for situations where the objects of interest (in this case the stations within each area) were described by measures of the abundance of different characteristics (Manly 2000). We used uniform row weights because we were interested in the comparison of the distribution of traits within stations. FCA ordinates samples on a multidimensional plane using Euclidean distance based on $\chi^{2}$ distance (Greenacre 1984). This maximizes the distances between samples. High weighting is given to rare or less well-represented values. In this study this was an acceptable procedure due to the need to represent variables that were particularly vulnerable to trawling and may thus be underrepresented in samples.

FCA results were presented by plotting the scores from the first 2 axes for each station and each modality. Since the station values are an average of the modality values and vice versa, it is usual to plot the scores for each on the same axis giving an ordination of both at the same time (Manly 2000). Stations that are closer together in the factor map have similar patterns of biomass distributions across modalities. Distances between the stations can therefore be interpreted in terms of changes in the proportional biomass of modal- ities. The area of the circles representing the stations on the plots indicates the trawling intensity $\left(\mathrm{yr}^{-1}\right)$ with larger circles indicating higher levels of trawling. To aid display and interpretation, the points representing the ecological and life history modalities were given the same arbitrary small size. There are no statistical significance tests that are customarily applied to the results of correspondence analysis.

Analysis of biomass and selected traits. The relationship between trawling intensity and the biomass of the modalities 'permanently attached', 'filter feeding', 'burrowing' and 'scavenging' for the 4 areas was described using least squares linear regression. These modalities were chosen as they were particularly linked to differences associated with trawling according to the multivariate analyses. Regression analysis was also performed on the biomass weighted modalities of the life history variables 'size' and 'longevity'. Biomasses and trawling intensity were $\log _{10}(\mathrm{n}+0.1)$ transformed before statistical analyses to normalize residuals, and examined visually for normality.

\section{RESULTS}

\section{Correlation between life history and ecological function}

There was a significant correlation between the life history and ecological function similarity matrices at the muddy area, FG $(\rho=0.16, p=0.018)$. There was no correlation between life history and ecological function similarity matrices of the species found in the other areas (DB: $\rho=0.075, p=0.179$; NW: $\rho=$ $-0.027, p=0.647$; LF: $\rho=-0.054, p=0.729)$. At $F G$, filter feeders had a low adult mobility and an age of $<2 y r$ at sexual maturity, and they were sexual spawners. Epifaunal animals generally have a pelagic life stage.

\section{FCA of ecological functional variables}

For each area more than $75 \%$ of the variation in the data was accounted for by the first 2 axes of the ordination. Most of the variation was contributed by the variable 'movement', followed by 'feeding type' and 'food' (Table 4). For DB, there was no consistent change in functional diversity between stations in relation to trawling intensity (Fig. 2A). For the other 3 areas there was an apparent separation of stations of different trawling intensities based on variations in trait compositions (Fig. 2B-D). As there is an association between 'feeding type' and 'food type', points representing these modalities are usually close to- 
Table 4. Relative inertia and correlation ratios of ecological function and life history variables on the first 2 axes of the fuzzy correspondence analysis. Correlation ratios represent proportions of total variance explained by each axis depicting separation among modalities of a variable

\begin{tabular}{|c|c|c|c|c|c|c|c|c|}
\hline & \multicolumn{2}{|c|}{ Dogger Bank } & \multicolumn{2}{|c|}{ Fladen Ground } & \multicolumn{2}{|c|}{ Long Forties } & \multicolumn{2}{|c|}{ North West Rough } \\
\hline & Axis 1 & Axis 2 & Axis 1 & Axis 2 & Axis 1 & Axis 2 & Axis 1 & Axis 2 \\
\hline \multicolumn{9}{|l|}{ Ecological function } \\
\hline Relative inertia (\%) & 41.28 & 34.08 & 52.30 & 35.69 & 68.10 & 22.11 & 65.96 & 12.98 \\
\hline \multicolumn{9}{|l|}{ Correlation ratios $(\%)$} \\
\hline Movement & 6.1 & 6.0 & 16.9 & 7.8 & 19.7 & 14.1 & 8.1 & 2.1 \\
\hline Position & 6.3 & 2.8 & 0.7 & 6.3 & 6.6 & 0.5 & 2.8 & 1.3 \\
\hline feeding type & 1.8 & 1.9 & 3.2 & 0.7 & 12.3 & 0.4 & 8.7 & 0.8 \\
\hline Food & 2.2 & 2.8 & 4.2 & 2.3 & 12.4 & 1.5 & 6.9 & 1.0 \\
\hline \multicolumn{9}{|l|}{ Life history variables } \\
\hline Relative inertia (\%) & 59.8 & 22.4 & 52.0 & 32.0 & 62.4 & 28.0 & 62.6 & 21.2 \\
\hline \multicolumn{9}{|l|}{ Correlation ratios $(\%)$} \\
\hline Size & 28.2 & 19.8 & 26.4 & 14.6 & 28.7 & 3.3 & 16.0 & 5.5 \\
\hline Longevity & 19.6 & 3.3 & 17.3 & 0.3 & 4.1 & 0.5 & 13.2 & 0.6 \\
\hline Age at maturity & 11.9 & 3.5 & 0.3 & 5.8 & 4.0 & 7.0 & 9.8 & 4.4 \\
\hline Reproductive type & 9.9 & 0.7 & 2.5 & 2.7 & 3.5 & 8.2 & 10.0 & 3.7 \\
\hline Reproductive frequency & 6.0 & 0.3 & 3.2 & 6.8 & 9.9 & 3.0 & 5.2 & 3.3 \\
\hline Dissemination & 0.2 & 0.7 & $1.0 \mathrm{a}$ & 0.9 & 8.4 & 0.6 & 0.9 & 1.3 \\
\hline
\end{tabular}

gether on the axes. For clarity, the points for 'food type' are therefore not included on the ordination plots illustrated. Stations with lower trawling intensities were distinguished by greater biomass of 'attached' (permanent and temporary) organisms at areas FG, LF and NW. These stations were also char- acterized by a higher proportional biomass of 'epifaunal species' and 'filter feeders'. In contrast, the stations that experienced higher trawling intensity at these areas were associated with a greater proportional biomass of 'infauna', 'burrowers' and 'scavenger/carrion feeders' and 'predators'.
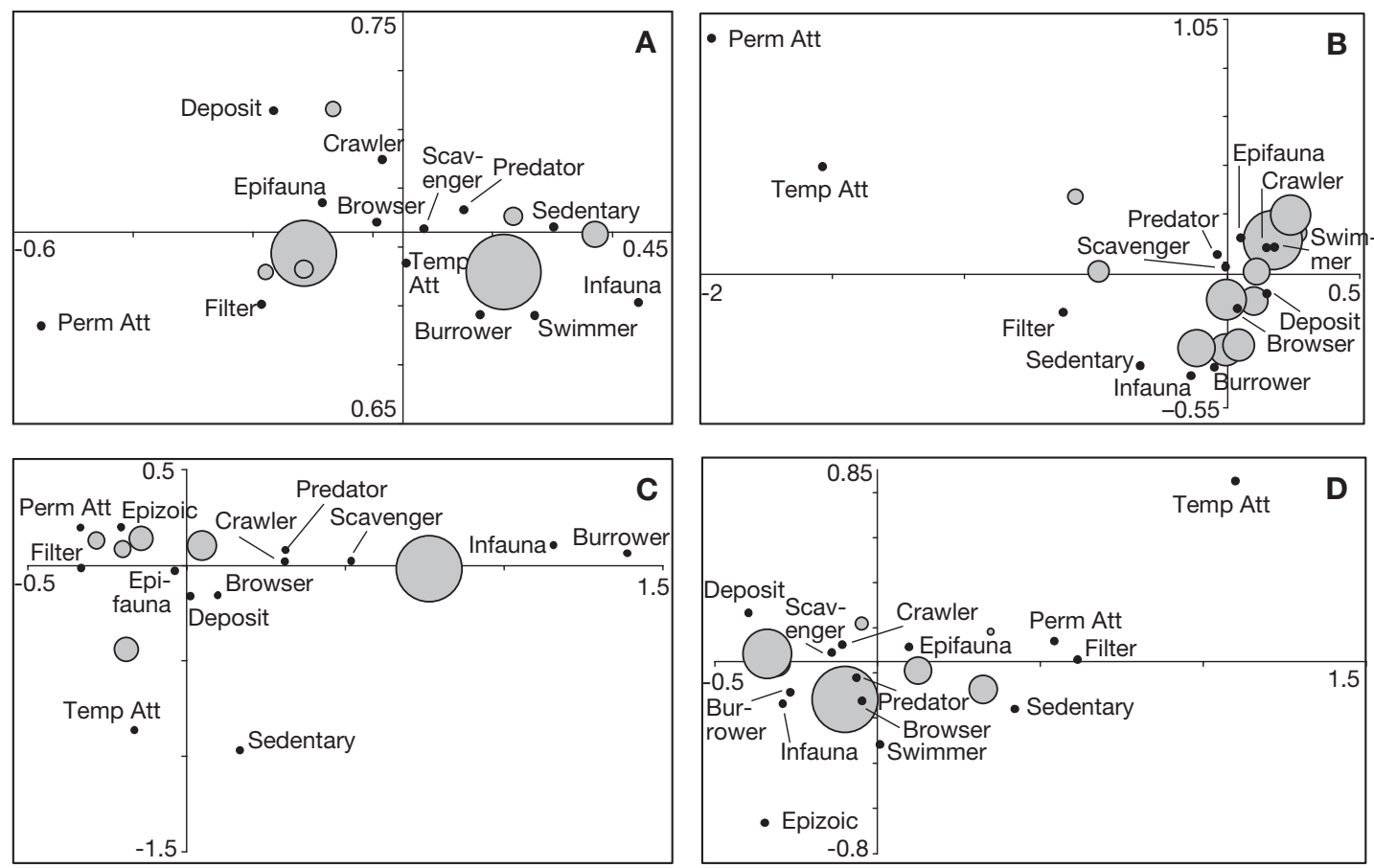

Fig. 2. Plots of ordination scores from fuzzy correspondence analysis of ecological variables for the 4 areas (A) Dogger Bank, (B) Fladen Ground, (C) Long Forties, (D) Northwest Rough. (O) Stations (area of circles: trawling intensity [yr ${ }^{-1}$ ]; larger circles indicate higher levels of trawling); $(\bullet)$ ecological and life history modalities. Perm att: permanently attached; temp att: temporarily attached. For interpretation of graphs, see section 'Relationship between functional composition and trawling intensity' in 


\section{FCA of life history variables}

For each study area greater than $80 \%$ of the variation in the data was accounted for by the first 2 axes of the factor ordination (Table 4). Examination of the correlation ratios showed that most of the variation was contributed by the variables 'size', 'longevity' and 'reproductive type'.

There was no separation of stations of varying trawling intensity by life history modalities at DB on the basis of the ordination of stations and modality scores from the FCA (Fig. 3). Separation of stations by life history modalities occurred to varying degrees at the other 3 areas (Fig. 3). This indicates that there were differences in proportional life history composition of the communities sampled in these stations and that these could be related to different degrees of trawling intensity. At areas FG, LF and NW, stations with lower trawling intensities were associated with a greater proportional biomass of long-lived and 'large' and 'very large' organisms. At NW there was a reduction in the proportion of biomass contributed by 'large' and 'very large' organisms along a gradient of increased trawling intensity. Longevity followed a similar pattern at this area with stations of lower trawling intensity associated with a greater proportional biomass of longer lived organisms. Corresponding with this the age at which sexual maturity was reached again declined with increasing trawling intensity.

At NW the reproductive types 'asexual', 'direct development' and 'semelparity' were better represented in stations with lower trawling intensities. Stations with lower trawling intensities at areas FG, LF and NW were associated with a higher proportional biomass of organisms that had no pelagic stage in their life cycle while stations with higher trawling intensities had greater proportions of migratory and highly mobile adults. Thus, in general, the least trawled sites tended to be distinguished by a higher proportional biomass of 'very large' and longer-lived organisms and

Table 5. Generalised Linear Model p-values relating biomass for selected modalities to Area (categorical) and trawling intensity (continuous)

\begin{tabular}{|lcrcc|}
\hline Group & $\mathrm{n}$ & $\mathrm{p}$ (Area) & $\begin{array}{c}\mathrm{p} \\
\text { (Trawling } \\
\text { intensity) }\end{array}$ & $\begin{array}{c}\mathrm{p} \text { (interaction } \\
\text { Area } \times \text { Trawling } \\
\text { intensity) }\end{array}$ \\
\hline Filter feeders & 33 & 0.005 & 0.002 & 0.91 \\
Permanent attached & 33 & $<0.001$ & 0.005 & 0.60 \\
Scavengers & 33 & 0.001 & 0.31 & 0.21 \\
Burrowers & 33 & 0.009 & 0.67 & 0.32 \\
Very small body size, <2 g & 33 & $<0.001$ & 0.85 & 0.47 \\
Large body size, 40-200 g & 33 & 0.087 & 0.046 & 0.76 \\
Longevity < 2 yr & 33 & 0.002 & 0.67 & 0.15 \\
Longevity $>10 \mathrm{yr}$ & 33 & $<0.001$ & 0.010 & 0.10 \\
\hline
\end{tabular}

those without a pelagic life stage than those stations with higher trawling intensities.

In Figs. $2 \& 3$ the relative positions of the functional attributes vary between locations, because the species identities and their relative contribution to biomass are different between areas. From Figs. 2 \& 3, it cannot be concluded if these differences are environmentally driven or related to the variation in trawling intensity between areas.

\section{Univariate relationships between trawling intensity and biomass}

Trawling significantly reduced the biomass of 'permanently attached' and 'filter feeding' species across the 4 areas (Fig. 4, Table 5). The biomass of 'scavengers' and 'burrowers' was not significantly affected by trawling. There was a significant negative effect of trawling on the biomass of long-lived and 'large' animals, while there was no effect of trawling on the biomass of short-lived and small animals (Fig. 5, Table 5).

\section{DISCUSSION}

This study indicates that there are effects of chronic bottom trawling disturbance on the functional composition of marine invertebrate communities at the scale of the fishery across a range of habitats. Changes in the functional composition of the benthic community that could be related to trawling intensity were found in 3 out of 4 areas, using both multivariate and univariate analyses. As changes in functional structure were consistent over 3 of the 4 areas sampled, and because stations were distributed over a relatively small area within these 4 areas, this suggests that trawling was the factor responsible for these changes rather than the effects of other environmental parameters. We found a significant correlation between life history and ecological function in the muddy FG area only. The reason why we found this relationship in the FG and not in the other areas remains unexplained. This indicates that in the FG, members of similar ecological functional groups have similar life histories, and therefore that trawling may affect ecological function indirectly through selective effects on animals with specific life histories. However, in the other 3 areas we did not find such a correlation, while we did find an effect of trawling on the functional composition in 2 of these areas. The lack of correlation between life history and ecological function in 

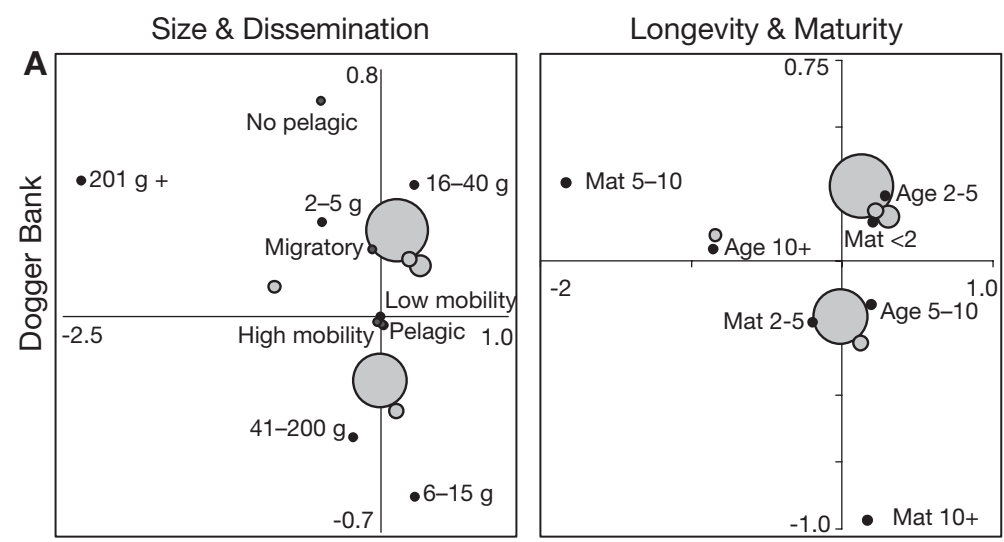

Reproductive type \& frequency
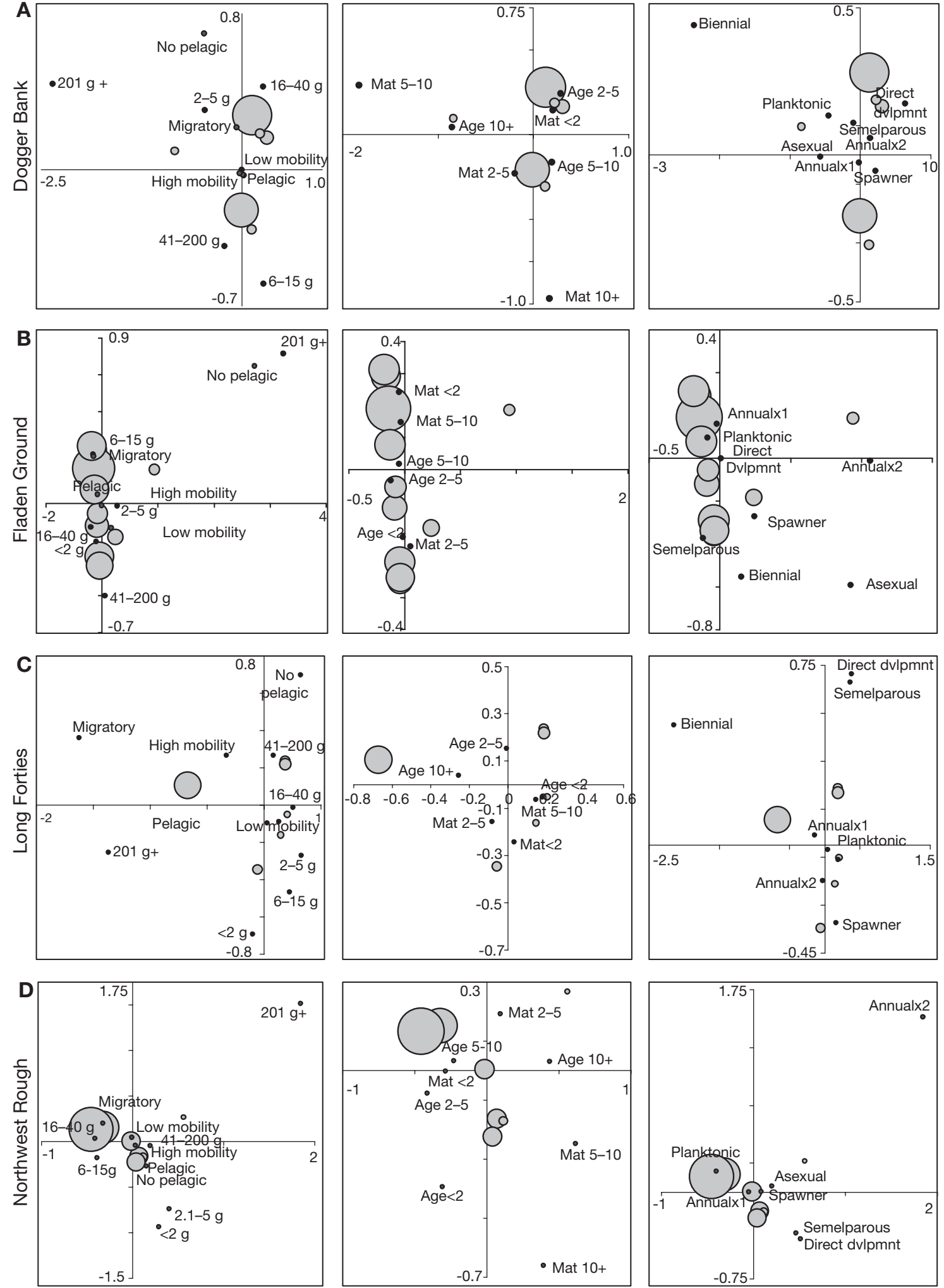

Fig. 3. Plots of ordination scores from fuzzy correspondence analysis of life history characteristics for the 4 areas (A) Dogger Bank, (B) Fladen Ground, (C) Long Forties, (D) North West Rough. The same ordination is presented 3 times per area to allow for plotting of positions of all superimposed modalities per variable. Mat: age at maturity; dvlpmnt: development. See Fig. 2 for details. For interpretation of graphs, see section 'Relationship between functional composition and trawling intensity' in 'Materials and methods' 


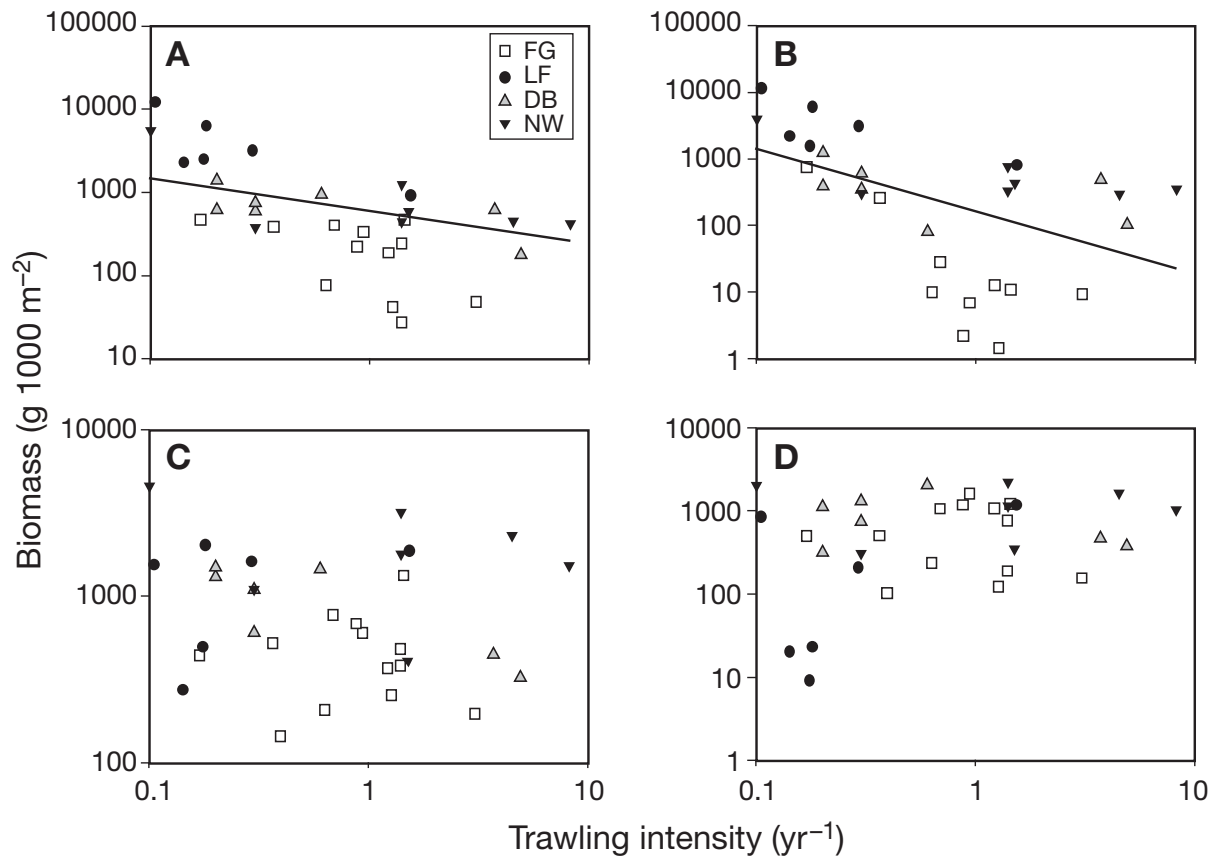

Fig. 4. Biomass versus trawling intensity for 4 ecological groups. (A) Filter feeders, (B) permanently attached, (C) scavengers, (D) burrowers. If significant, the common regression relationship between trawling intensity and biomass for the 4 areas is drawn. FG: Fladen Ground; LF: Long Forties; DB: Dogger Bank; NW: Northwest Rough

these areas means this could not be explained by changes in abundance of functional groups in which all species had similar life histories, and suggests that there is another reason why ecologically similar animals were also similarly vulnerable to trawling. In the present study, trawling appears to affect the functional composition of benthic communities in the North Sea in similar ways in 3 out of 4 habitats according to the multivariate FCA, and in all 4 areas, independent of sediment types and depths, using a univariate analysis.
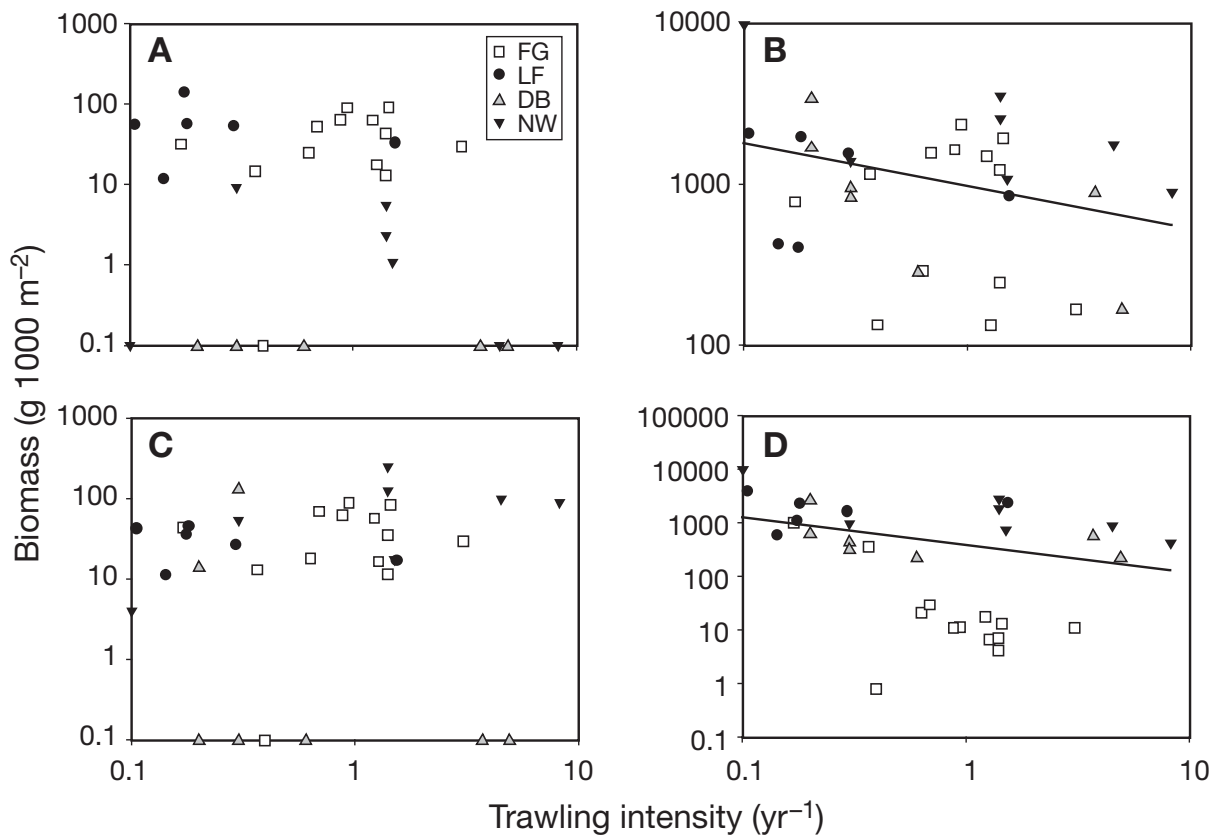

Fig. 5. Biomass versus trawling intensity for 4 life history groups: (A) Very small $<2$ g, (B) Large 40 to $200 \mathrm{~g}$, (C) Longevity <2 yr, (D) Longevity $10+$ yr. Data were +0.1 transformed to allow for the plotting of 0 -values on the log-scale. If significant, the common regression relationship between trawling intensity and biomass for the 4 areas is drawn. FG: Fladen Ground; LF: Long Forties; DB: Dogger Bank; NW: Northwest Rough 
Stations with lower trawling intensities had a greater proportional biomass of attached epifauna and filter feeders. Although previous studies have shown that these functional types are particularly vulnerable to trawling disturbance in specific habitats (e.g. Collie et al. 2000a, Bradshaw et al. 2003), no previous studies have shown this to be a general effect of trawling over larger spatial scales in different habitats. The benthic communities sampled from stations with higher trawling intensities were characterised by greater proportions of deposit feeders, burrowers and scavengers. Scavenging species congregate in the tracks made by a trawl pass to feed on exposed and damaged or dead organisms (Kaiser \& Spencer 1996, Collie et al. 1997, Ramsay et al. 1998, Groenewold \& Fonds 2000, Morello et al. 2005) and are often the dominant fauna in areas subjected to high levels of physical disturbance (Collie et al. 1997, Ramsay et al. 2000). Because we cannot calculate the exact trawling history in the months previous to sampling of the stations using VMS effort data, the relative increase in scavengers observed in this study may be due to both a short term response to trawling or due to a long term increase in scavenging species. A comparison of historical with more recent data suggested that a long-term increase in scavenging species has occurred (Rumohr \& Kujawski 2000).

Changes in the life history composition of communities towards smaller animals due to disturbance can be expected from ecological theory (Dickie et al. 1987), and has been found for benthic invertebrates in earlier studies (e.g. Jennings et al. 2001, McConnaughey et al. 2005). Here we found that benthic communities at more heavily trawled sites had a higher proportional biomass of smaller, shorter-lived species that reproduce sexually and that produce pelagic larvae.

Attached epifaunal filter feeders were particularly vulnerable to trawling (Collie et al. 2000a, Pitcher et al. 2000, Bradshaw et al. 2003). These have been shown to affect benthic biodiversity by providing small scale habitat complexity, acting as refugia and as settlement substrata (Bradshaw et al. 2003). Filter feeders capture large quantities of particles and phytoplankton from the water column and may directly and indirectly regulate primary and secondary production (Gili \& Coma 1998). Suspension-feeding bivalves can remove 60 to $90 \%$ of suspended matter, depending on particle size, from the horizontal particle flux (Loo \& Rosenberg 1989). By ejecting unsuitable particles, such as mucous wrapped pseudofaeces, bivalves also increase the rate of particle deposition to the seafloor and stimulate microbial production (Newell 2004). Reduction of biomass within these groups may alter the pattern of resource use in the community and change energy flow through the benthic ecosystem.
DB was the only area where there were no apparent differences in the functional composition of communities that experienced different levels of trawling. The benthic communities at the DB area may display fewer functional changes due to trawling effects because they are already adapted to high levels of natural disturbance (Kaiser \& Spencer 1996, Hiddink et al. 2006). $\mathrm{DB}$ is the shallowest site with sand sediments and hence may be subjected to greater disturbance due to currents and waves than the other areas that have similar sediments but are deeper, such as NW. Small scale experimental trawling studies also showed that the initial impact of trawling was least on sand sediments (Collie et al. 2000b).

Changes that alter the functional diversity within an ecosystem alter resource use and would be expected to have an effect on the productivity of the ecosystem (Tilman 2001). If functional diversity is reduced by depletion or deletion of a functional group, then certain resources would be under exploited or unexploited relative to undisturbed communities or redirected to other compartments such as the microbial loop (Diaz \& Cabido 2001, Baird et al. 2004). This would be expected to lead to a reduction in the productivity of the ecosystem indicated by a reduction in biomass. Because there was no relationship between life history and ecological function in the DB, LF and NW areas, functional diversity was predicted to be more robust as a result of functional redundancy. If members of functional groups have diverse life history strategies, then density-dependent compensation by resilient members of the same functional group may stabilise functional diversity. In these areas, it could be predicted that productivity would be affected less by trawling intensity. However, replacements by functionally similar but more resilient species to trawling do not appear to have occurred within these areas. A reason for this may be that competition is not the most important structuring influence in these ecosystems. If species within a functional group do not compete for resources there may not be a reciprocal increase in more resistant species when larger species within the group are removed. In addition, the ecological features of species could also directly affect their vulnerability to trawling impacts, e.g. filter feeders have to live close to the sediment surface. In the case of attached-filter feeders, it is easy to imagine how their sedentary and emergent position at the sediment-water interface makes this group particularly vulnerable to trawling (e.g. Collie et al. 2000a, Hall-Spencer et al. 2002, Bordehore et al. 2003).

Because the $2 \mathrm{~m}$ beam trawl is not particularly efficient and only samples a subset of the whole benthic invertebrate community, our results are primarily relevant for epifaunal invertebrates. The biomass and spe- 
cies richness of infauna is strongly underestimated by this trawl (catch efficiency likely to be lower than 15\%, Reiss 2005) and this is likely to increase the variation in the biomass estimates of infauna. However, we do not expect a bias in sampling efficiency of infauna and other functional groups that relates to commercial trawling intensity.

Because of logistical constraints, the 4 areas were sampled on 3 different cruises in different months over a 15 mo period. This means that differences in the response to trawling between areas can be due to both seasonal and annual fluctuations in the relative biomasses of different functional groups. This may have particularly affected life history traits, as the biomass of short-lived small animals is likely to be related to their seasonal reproduction cycles. The DB area was the only area where we did not find an effect of trawling on the relative biomass of different functional groups. However, this area was sampled in the same cruise as for LF, for which an effect was found. This suggests that the precise moment of sampling did not strongly affect our conclusions. Another reason why sampling season may not have greatly affected our conclusions is that community recovery from trawling is likely to take several years (Hermsen et al. 2003, Blyth et al. 2004, Murawski et al. 2004, Beukers-Stewart et al. 2005), and on a timescale of 15 mo trawling effects are likely to be larger than seasonal and annual variations.

We assumed that species exhibited the same biological traits throughout the North Sea, regardless of the habitat, as it is impossible to find habitat dependent trait information for most species. This may have caused an overestimate of the effect of trawling on functional composition as this means we did not allow for adaptation of species to local conditions.

Because of the practical impossibility of sorting the mixture of bushy hydroids and bryozoans into separate phyla and because of the difference in their life history, they were excluded from RELATE and life history trait analysis. This may have affected the results for these analyses in ways that are difficult to anticipate, in particular in LF where foliose hydroids and bryozoans were very abundant.

Different weighting was placed on the rare functional groups by different analyses. We excluded species that were rare in all areas from the analysis to reduce the demand for functional data. On the other hand, FCA weighs functional groups in extremes of data distribution stronger. Patterns from multivariate analyses should therefore be corroborated by univariate analyses (e.g. regression of group biomass against trawling intensity) to clarify observed patterns.

The present study indicates the usefulness of fuzzy coded traits and FCA as a way of using information on species sensitivities and ecological function, together with their distribution, to measure changes in ecosystem functioning. The use of this technique enabled changes in the proportional representation of functional traits to describe changes in likely ecological functioning due to trawling. FCA and univariate regression analysis can be used as complementary analysis methods, given that FCA analyses changes in the proportions of the biomasses of the different modalities, while the regression analysis examines absolute changes in the biomass. Interpretation of the results of a FCA is rather subjective, and should therefore be primarily used as an exploratory tool in conjunction with subsequent univariate analyses to verify the observed trends.

Analysis of fuzzy coded traits appears to be useful as a tool to measure the impact of anthropogenic impacts that could also be used to assess the outcome of management strategies on ecosystem functioning. Identification of the threshold levels of fishing that benthic communities can withstand before functioning is altered would be pertinent to guide decisions under an ecosystem approach to management. One clear outcome is that fishing effort ideally should be directed away from areas where functional structure and productivities would be highly altered by trawling (such as LF in this study).

The analysis of functional diversity highlights the necessity of accurate biological and ecological information. Data are currently most readily available for animals with a high economic value reflecting the bias of human interest in marine environments. There is a need for continuing autecological studies of marine organisms to further our knowledge of fundamental life history traits and ecological requirements of species to inform scientific work and policy decisions.

Acknowledgements. This study was funded by DEFRA under contract MF0731. The VMS data were provided by DEFRA and RIVO in a raw, uninterpreted form. We thank G. Piet (RIVO), P. Eastwood and C. Mills (CEFAS) for supplying the VMS data. Officers and crew of RV 'Prince Madog', RV 'CEFAS Endeavour' and RV 'Corystes', I. Rees, H. Hinz, M. Galanidi, F. van Gent, K. Barker, R. Wilton, J. Gascoigne, D. Carlin, C. Mills, N. Dulvy, K. Warr, T. Dinmore, M. Schratzberger, C. Firmin, A. Nicholls and W. Meadows are thanked for their help during the cruises. We thank C.H. Peterson, L. Watling and an anonymous reviewer for comments that improved an earlier version of this paper.

\section{LITERATURE CITED}

Auster PJ, Langton RW (1999) The effects of fishing on fish habitat. In: Benaka LR (ed) Fish habitat: essential fish habitat and rehabilitation. American Fisheries Society, Hartford, CT, p 150-187

Baird D, Christian RR, Peterson CH, Johnson GA (2004) Consequences of hypoxia on estuarine ecosystem function: 
energy diversion from consumers to microbes. Ecol Appl 14:805-822

Beukers-Stewart BD, Vause BJ, Mosley MWJ, Rossetti HL, Brand AR (2005) Benefits of closed area protection for a population of scallops. Mar Ecol Prog Ser 298:189-204

Blyth RE, Kaiser MJ, Edwards-Jones G, Hart PJB (2004) Implications of a zoned fishery management system for marine benthic communities. J Appl Ecol 41:951-961

Bordehore C, Ramos-Espla AA, Riosmena-Rodriguez R (2003) Comparative study of 2 maerl beds with different otter trawling history, southeast Iberian Peninsula. Aquat Conserv-Mar Freshw Ecosyst 13:S43-S54

Bradshaw C, Collins P, Brand AR (2003) To what extent does upright sessile epifauna affect benthic biodiversity and community composition? Marine Biology 143:783-791

Bremner J, Frid CLJ, Rogers SI (2003a) Assessing marine ecosystem health: the long-term effects of fishing on functional biodiversity in North Sea benthos. Aquat Ecosyst Health Manag 6:131-137

Bremner J, Rogers SI, Frid CLJ (2003b) Assessing functional diversity in marine benthic ecosystems: a comparison of approaches. Mar Ecol Prog Ser 254:11-25

Brey T (1999) Growth performance and mortality in aquatic macrobenthic invertebrates. Adv Mar Biol 35:153-223

British Geological Survey (2002) Sea-bed sediments around the United Kingdom Digital Data Version 1.0. British Geological Survey, Nottingham

Chapin FS, Walker BH, Hobbs RJ, Hooper DU, Lawton JH, Sala OE, Tilman D (1997) Biotic control over the functioning of ecosystems. Science 277:500-504

Chevenet F, Doledec S, Chessel D (1994) A fuzzy coding approach for the analysis of long-term ecological data. Freshw Biol 31:295-309

Clarke KR, Warwick RM (1994) Change in marine communities: an approach to statistical analysis and interpretation. Natural Environmental Research Council, Plymouth Marine Laboratory, Plymouth

Collie JS, Escanero GA, Valentine PC (1997) Effects of bottom fishing on the benthic megafauna of Georges Bank. Mar Ecol Prog Ser 155:159-172

Collie JS, Escanero GA, Valentine PC (2000a) Photographic evaluation of the impacts of bottom fishing on benthic epifauna. ICES J Mar Sci 57:987-1001

Collie JS, Hall SJ, Kaiser MJ, Poiner IR (2000b) A quantitative analysis of fishing impacts on shelf-sea benthos. J Anim Ecol 69:785-798

Diaz S, Cabido M (2001) Vive la difference: plant functional diversity matters to ecosystem processes. Trends Ecol Evol 16:646-655

Dickie LM, Kerr SR, Boudreau PR (1987) Size-dependent processes underlying regularities in ecosystem structure. Ecol Monogr 57:233-250

Dinmore TA, Duplisea DE, Rackham BD, Maxwell DL, Jennings S (2003) Impact of a large-scale area closure on patterns of fishing disturbance and the consequences for benthic communities. ICES J Mar Sci 60:371-380

Emmerson MC, Solan M, Emes C, Paterson DM, Raffaelli D (2001) Consistent patterns and the idiosyncratic effects of biodiversity in marine ecosystems. Nature 411:73-77

Engel J, Kvitek R (1998) Effects of otter trawling on a benthic community in Monterey Bay National Marine Sanctuary. Conserv Biol 12:1204-1214

Gili JM, Coma R (1998) Benthic suspension feeders: their paramount role in littoral marine food webs. Trends Ecol Evol 13:316-321

Greenacre MJ (1984) Theory and applications of correspondence analysis. Academic Press, London
Groenewold S, Fonds M (2000) Effects of benthic scavengers of discards and damaged benthos produced by the beamtrawl fishery in the southern North Sea. ICES J Mar Sci 57:1395-1406

Gross K, Cardinale BJ (2005) The functional consequences of random vs. ordered species extinctions. Ecol Lett 8:409-418

Hall SJ (1999) The effect of fishing on marine ecosystems and communities. Blackwell, Oxford

Hall-Spencer J, Allain V, Fossa JH (2002) Trawling damage to northeast Atlantic ancient coral reefs. Proc R Soc Lond Ser B Biol Sci 269:507-511

Hermsen JM, Collie JS, Valentine PC (2003) Mobile fishing gear reduces benthic megafaunal production on Georges Bank. Mar Ecol Prog Ser 260:97-108

Hiddink JG, Jennings S, Kaiser MJ, Queirós AM, Duplisea DE, Piet GJ (2006) Cumulative impacts of seabed trawl disturbance on benthic biomass, production and species richness in different habitats. Can J Fish Aquat Sci 63: 721-736

Holland DS, Sutinen JG (2000) Location choice in New England trawl fisheries: old habits die hard. Land Econ 76:133-149

Jennings S, Alvsvag J, Cotter AJR, Ehrich S and 5 others (1999a) Fishing effects in northeast Atlantic shelf seas: patterns in fishing effort, diversity and community structure. III. International trawling effort in the North Sea: an analysis of spatial and temporal trends. Fish Res 40: 125-134

Jennings S, Lancaster J, Woolmer A, Cotter J (1999b) Distribution, diversity and abundance of epibenthic fauna in the North Sea. J Mar Biol Assoc UK 79:385-399

Jennings S, Dinmore TA, Duplisea DE, Warr KJ, Lancaster JE (2001) Trawling disturbance can modify benthic production processes. J Anim Ecol 70:459-475

Jennings S, Nicholson MD, Dinmore TA, Lancaster J (2002) The effect of chronic trawling disturbance on the production of infaunal communities. Mar Ecol Prog Ser 243: 251-260

Kaiser MJ, De Groot SJ (2000) The effects of fishing on nontarget species and habitats: biological, conservation and socio-economic issues. Blackwell Science, Oxford.

Kaiser MJ, Spencer BE (1996) The effects of beam-trawl disturbance on infaunal communities in different habitats. J Anim Ecol 65:348-358

Kaiser MJ, Rogers SI, McCandless DT (1994) Improving quantitative surveys of epibenthic communities using a modified $2 \mathrm{~m}$ beam trawl. Mar Ecol Prog Ser 106:131-138

Kaiser MJ, Ramsay K, Richardson CA, Spence FE, Brand AR (2000) Chronic fishing disturbance has changed shelf sea benthic community structure. J Anim Ecol 69:494-503

Kaiser MJ, Clarke KR, Hinz H, Austen MCV, Somerfield PJ, Karakassis I (2006) Global analysis of response and recovery of benthic biota to fishing. Mar Ecol Prog Ser 311:1-14

Larsen TH, Williams NM, Kremen C (2005) Extinction order and altered community structure rapidly disrupt ecosystem functioning. Ecol Lett 8:538-547

Loo LO, Rosenberg R (1989) Bivalve suspension-feeding dynamics and benthic pelagic coupling in an eutrophicated marine bay. J Exp Mar Biol Ecol 130:253-276

Manly B (2000) Multivariate statistical methods: a primer. Chapman \& Hall, London

McConnaughey RA, Mier KL, Dew CB (2000) An examination of chronic trawling effects on soft-bottom benthos of the eastern Bering Sea. ICES J Mar Sci 57:1377-1388

McConnaughey RA, Syrjala SE, Dew CB (2005) Effects of chronic bottom trawing on the size structure of soft-bottom 
benthic invertebrates. In: Barnes PW, Thomas JP (eds) Benthic habitats and the effects of fishing, Vol 41. American Fisheries Society, Bethesda, MD, p 425-437

Morello EB, Froglia C, Atkinson RJA, Moore PG (2005) Impacts of hydraulic dredging on a macrobenthic community of the Adriatic Sea, Italy. Can J Fish Aquat Sci 62:2076-2087

Murawski SA, Rago P, Fogarty M (2004) Spillover effects from temperate marine protected areas. In: Shipley JB (ed) Aquatic protected areas as fishery management tools. American Fisheries Society, Symposium 42, Bethesda MD, p 167-184

Murawski SA, Wigley SE, Fogarty MJ, Rago PJ, Mountain DG (2005) Effort distribution and catch patterns adjacent to temperate MPAs. ICES J Mar Sci 62:1150-1167

Newell RIE (2004) Ecosystem influences of natural and cultivated populations of suspension-feeding bivalve molluscs: a review. J Shellfish Res 23:51-61

Olafsson EB, Peterson CH, Ambrose WG (1994) Does recruitment limitation structure populations and communities of macroinvertebrates in marine soft sediments - the relative significance of presettlement and postsettlement processes. Oceanogr Mar Biol 32:65-109

Palanques A, Guillen J, Puig P (2001) Impact of bottom trawling on water turbidity and muddy sediment of an unfished continental shelf. Limnol Oceanogr 46:1100-1110

Peterson CH, Summerson HC, Fegley SR (1987) Ecological consequences of mechanical harvesting of clams. Fish Bull 85:281-298

Pikitch EK, Santora C, Babcock EA, Bakun A and 17 others (2004) Ecosystem-based fishery management. Science 305:346-347

Pitcher CR, Poiner IR, Hill BJ, Burridge CY (2000) Implications of the effects of trawling on sessile megazoobenthos on a tropical shelf in northeastern Australia. ICES Mar Sci 57:1359-1368

Queirós AM, Hiddink JG, Hinz H, Kaiser MJ (2006) The effects of chronic bottom trawling disturbance on biomass, production and size spectra of invertebrate infauna communities from different habitats. J Exp Mar Biol Ecol 335: 91-103

Ramsay K, Kaiser MJ, Hughes RN (1998) Responses of benthic scavengers to fishing disturbance by towed gears in different habitats. J Exp Mar Biol Ecol 224:73-89

Ramsay K, Kaiser MJ, Rijnsdorp AD, Craeymeersch JA, Ellis J (2000) Impact of trawling on populations of the invertebrate scavenger Asterias Rubens. In: Kaiser MJ, De Groot SJ (eds) Effects of fishing on non-target species and habi-

Editorial responsibility: C. H. Peterson (Contributing Editor), Morehead City, North Carolina, USA tats: biological conservation and socio-economic issues. Blackwell Science, Oxford

Reiss H (2005) Catch efficiency of a standardized $2 \mathrm{~m}$ beam trawl (Epicatch). ICES Benthos Ecology Working Group 2005 Report. Annex 6: ICES CM 2005/E:07, p 48

Rijnsdorp AD, Vingerhoed B (2001) Feeding of plaice Pleuronectes platessa L. and sole Solea solea (L.) in relation to the effects of bottom trawling. J Sea Res 45:219-229

Robinson LA, Frid C (2005) Extrapolating extinctions and extirpations: search for a pre-fishing state of the benthos. In: Barnes PW, Thomas JP (eds) Benthic habitats and the effects of fishing. American Fisheries Society, Bethesda, MD, p 619-628

Rumohr H, Kujawski T (2000) The impact of trawl fishery on the epifauna of the southern North Sea. ICES J Mar Sci 57:1389-1394

Sinclair M, Valdimarsson G (2003) Responsible fisheries in the marine ecosystem. CABI publishing, Cambridge MA

Solan M, Kennedy R (2002) Observation and quantification of in situ animal-sediment relations using time-lapse sediment profile imagery (t-SPI). Mar Ecol Prog Ser 228: 179-191

Solan M, Cardinale BJ, Downing AL, Engelhardt KAM, Ruesink JL, Srivastava DS (2004) Extinction and ecosystem function in the marine benthos. Science 306: $1177-1180$

Stearns SC (1992) The evolution of life histories. Oxford University Press, Oxford

Thioulouse J, Chessel D, Doledec S, Olivier JM (1997) ADE-4: a multivariate analysis and graphical display software. Stat Comput 7:75-83

Thrush SF, Dayton PK (2002) Disturbance to marine benthic habitats by trawling and dredging: implications for marine biodiversity. Annu Rev Ecol Syst 33:449-473

Thrush SF, Hewitt JE, Cummings VJ, Dayton PK and 6 others (1998) Disturbance of the marine benthic habitat by commercial fishing: impacts at the scale of the fishery. Ecol Appl 8:866-879

Tilman D (2001) Functional diversity. In: Levin SA (ed) Encyclopedia of biodiversity, Vol 3. Academic Press, San Diego CA, p 109-120

Trimmer M, Petersen J, Sivyer DB, Mills C, Young E, Parker ER (2005) Impact of long-term benthic trawl disturbance on sediment sorting and biogeochemistry in the southern North Sea. Mar Ecol Prog Ser 298:79-94

Watling L, Norse EA (1998) Disturbance of the seabed by mobile fishing gear: a comparison to forest clearcutting. Conserv Biol 12:1180-1197

Submitted: June 3, 2005; Accepted: December 15, 2006 Proofs received from author(s): July 3, 2006 